\title{
SCIENCE
}

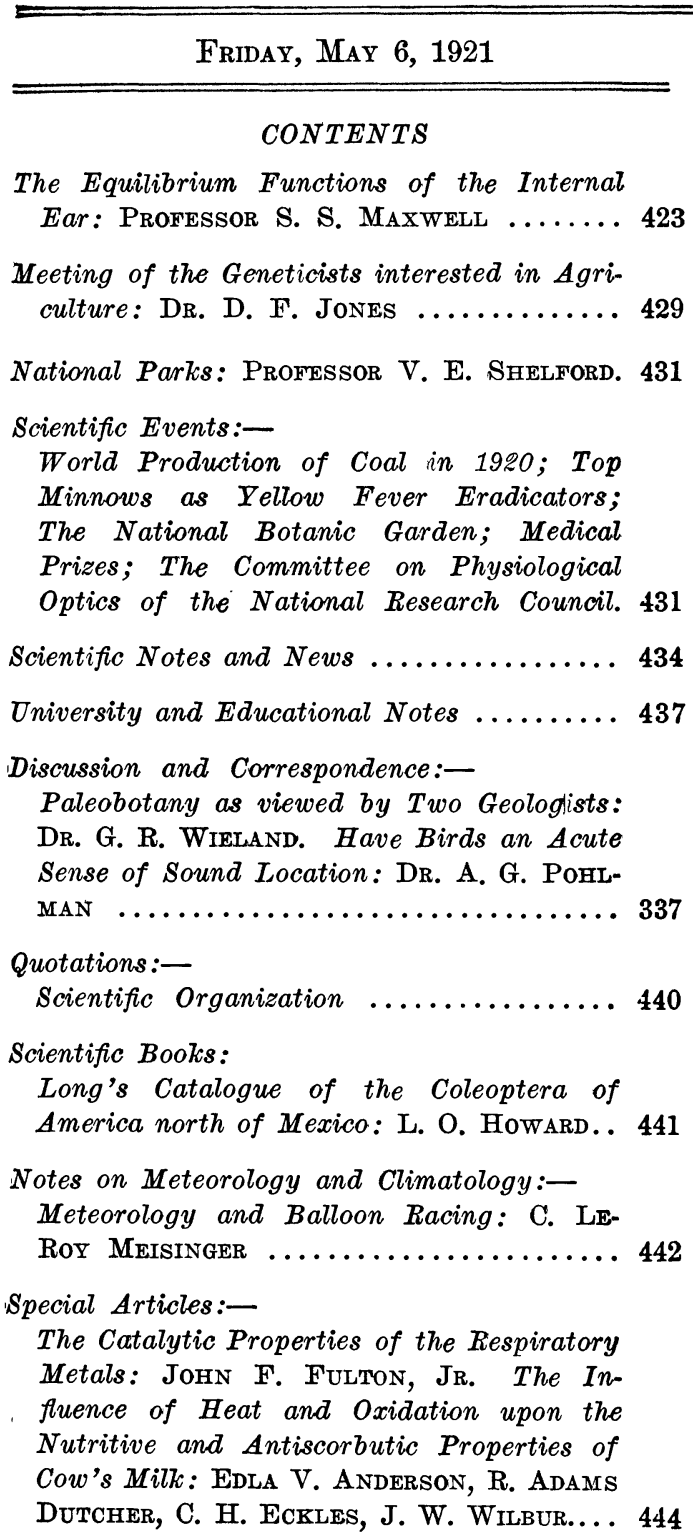

MSS. intended for publication and books, etc., intended for review should be sent to The Editor of Science, Garrison-onHudson, N. Y.

\section{THE EQUILIBRIUM FUNCTIONS OF THE INTERNAL EAR ${ }^{1}$}

IN this paper I have not attempted to survey the whole range of present-day problems on the functions of the labyrinth but have confined myself to some phases of two fundamental questions. (1) What and how much differentiation of function can be proved to exist in the different labryinthine structures concerned in equilibrium? (2) How does movement or change of position of the body give rise to the excitation process in the labyrinth?

I wish to state at the outset that merely for the sake of brevity specific mention will not be made of the reasons for assigning the functions discussed to the inner ear rather than to the movement of retinal images or to other sources of sensory stimuli, but must have it understood that those possible errors have not been left uncontrolled. Furthermore I have dealt with the phenomena objectively, because the experimental work which can throw light on these questions has necessarily been done upon animals in which the postulation of subjective sensations is unsafe or unnecessary. Furthermore I have not been unmindful of the fact that the reactions in the form of compensatory movements and forced positions include the simultaneous activity of many muscle groups, but I have used the compensatory movements of the eyes as the most convenient index of the labyrinthine reflexes, and also as the simplest to describe.

The labyrinth of the higher vertebrates must be used in the solution of many yet unsolved problems, but for the two fundamental questions now before us it presents insuperable difficulties. On the other hand the ears

1 Read before a joint session of the American Society of Naturalists and American Society of Zoologists, December 30, 1920. 
of Selachians are extremely favorable objects for experiment because of the relatively large size of their parts, their anatomical arrangements which permit the stimulation or extirpation of single portions, the ease and clearness with which operations can be performed through the cartilaginous skull, and the machine-like definiteness with which compensatory movements occur in these animals.

The compensatory movements of the eyes and fins of the dogfish were first accurately described by Loeb (1891). Lee (1893) made a very detailed study of these movements in response to rotation about the different body axes, and laid emphasis on the precision with which similar movements resulted from stimulation of the ampullæ of the different canals.

\section{THE SEMICIRCULAR CANALS}

\section{(a) Stimulation Experiments}

Lee's description of the results of stimulation of the individual ampullæ is very specific and I (1910) could confirm it in every particular. In brief the results may be thus stated: Stimulation of the ampulla of the right horizontal canal causes both eyes to turn to the left, the same movements as that which occurs when the animal is rotated to the right about its dorsoventral axis. Stimulation of the ampulla of the right anterior vertical canal causes the right eye to be elevated, the left eye to be depressed, and both eyes to roll backward on their axis; these movements are similar to those which occur when the animal is rotated head downward and to the right, that is, in the plane of the canal stimulated. When the ampulla of the posterior vertical canal is stimulated the right eye is elevated, the left eye is depressed and both eyes roll forward on their axes. These movements are identical with those which result from tilting the head upward and to the right, that is, a rotation in the plane of the posterior vertical canal. Of course, the stimulation of the symmetrically placed canals of the other side would merely transpose the use of the words left and right in this description. Ampullæ are exceedingly sensitive to mechanical stim- ulation. The results are absolutely clear and definite.

\section{(b) Extirpation}

On the basis of the above experiments Lee believed to have proof of the correctness of the Mach-Breuer assumption that the semicircular canals constitute the organ for the dynamic functions of the labyrinth. He attempted to put them out of function by cutting the ampullar nerves, or in some instances by destroying the ampullæ. He states that after cutting the nerves of all four vertical canals compensatory movements are wanting to all rotations in vertical planes, although compensation may be retained to rotation in a horizontal plane. Lyon (1899) on the other hand reported compensatory motions in response to all three rotations, after removal of all six ampullæ. I have developed a very simple and certain method of removal of the ampullæ, and I have repeated these experiments many times $(1910,1919)$ with the most complete regularity of results. I found that contrary to Lee's statement after removal of the ampullæ of the four vertical canals, or indeed of all six ampullæ, good compensatory movements occur to rotations around the longitudinal or transverse axis, but I have never yet seen the compensatory movements to rotation in the horizontal plane retained after removal of the ampullæ of the horizontal canals. Anyone who will take the trouble to repeat these experiments using my method will be able to see for himself that after loss of all the semicircular canals the labyrinth retains all its static functions, and all its dynamic functions except the response to rotation in a horizontal plane. The dynamic functions then are not confined to the semicircular canals.

\section{THE OTOLITH ORGANS}

\section{(a) Extirpation}

Experiments by rernoval of the otoliths have been carried on by many observers. Loeb (1891) found that scratching out the otoliths completely from the vestibule had much the same effect as section of the eighth 
nerve. Lee (1893) reported that when the otoliths were removed from both ears compensatory movements were perhaps weakened but were not completely done away with; but that on the other hand the compensatory position was not retained after the movement ceased. Parker (1909) and I (1910) both found that the removal of the large otolith of the sacculus had no effect whatever on the equilibrium reactions, static or dynamic. Moreover I found that after removal of the otoliths from the sacculus and in addition all the six ampullæ good compensatory motions occurred to rotations in all planes except the horizontal if only the little otolith of the recessus utriculi remained uninjured. If now I removed the otolith of the recessus also every trace of labyrinthine reaction permanently disappeared. It made no difference in the result, however, if I omitted the removal of the saccular otolith.

The removal of the otolith from the recessus of the utricle without too great damage to the connection of the utriculus with the mouths of the anterior vertical and horizontal canals, especially the latter, was so great that at first it seemed impossible. In my earlier experiments I was puzzled by the fact after complete removal of the otolith the ampulla of the horizontal canal always ceased to function. When at last $I$ was able to make a small incision through the delicate wall of the utriculus and wash out the otolith with a fine pipette I found not only that compensatory movements occurred in response to rotations in all planes, but that the compensatory positions were retained. Thus it becomes apparent that not only the otolith-organs without the ampullæ but also the ampullæ without the otolith-organs possess both dynamic and static functions. I may say here that in either case, after loss of the ampullæ or after loss of the otoliths, the reactions are noticeably slower and weaker than in the normal animal; evidently the two sets of structures . reinforce each other.

\section{(b) Stimulation Experiments}

Stimulation experiments on the otolithorgans have been attempted by many ob- servers but usually with inconstant, contradictory or negative results. Kubo (1906), however, reported very definite responses to stimulation by the application of pressure to the otolith. According to his statements the otoliths have definitely localized functions corresponding to those of the semicircular canals. These localizations corresponded to the statement of Breuer that the otoliths like the semicircular canals are arranged in three planes in space, each responding to motion in its own plane. Kubo states that the otolith of the utriculus when pushed anteriorly causes the eyes to roll backward, that is, to rotate on their axis, nasal pole up, which is the compensatory movement occurring when the head is tilted downward. Moving this otolith backward had no effect. In an analogous manner moving the large otolith of the sacculus backward gave the same movement as tilting the head up, and pushing the same otolith outwards from the median line gave the same reaction as that which comes from rotating the body to the same side around the longitudinal axis. In the light of our present knowledge Kubo's results are perfectly easy to understand, but are of absolutely no scientific value. His experiments were made without removing the ampullæ and he specifically states that they succeeded best when performed without removing "the membranous capsule of the gelatinous mass." In each case the result was just what would occur when he accidentally produced a change of tension on the nearest ampulla.

In order to study the effect of stimulation of any of the labyrinthine structures it is, of course, necessary to make sure that the structure in question is really the one in which the excitation takes place, since, as we have seen, all the compensatory movements which can be excited through the otolith organs in the absence of the semicircular canals can also be excited through the semicircular canals in the absence of the otolith organs. It is then evidently useless to attempt to determine the action of the otolith by stimulation experiments so long as the ampullæ of the canals are in place. The only completely 
convincing demonstration of the otolith function is that which can be obtained in the absence of all other parts which could give the same reaction. This $I$ have been able to accomplish in the most definite way (1920b).

My experiments on the otolith have been made on several species of sharks and rays. The most favorable animal for this purpose is the shovel-nosed ray or guitarfish, Rhinobatus productus. I removed all three semicircular canals with their ampullæ and then washed out the large, soft, friable otolith of the sacculus. There now remained only the small otolith of the recessus. This otolith is shaped somewhat like a plano-convex or concavo-convex lens and rests in a concave depression in which it fits much like one saucer standing in another. The concavity is lined with the characteristic macular epithelium with its hair cells. I found that if I pressed on the anterior side of this otolith the eyes rolled forward on their axes, anterior pole downward, that is, they made the same movement which occurs when the head is tilted upward. If I pressed on the hinder margin of the otolith the eyes rolled backward on their axes, the movement which occurs when the head is tilted downward. Pressure applied to the right margin of the otolith caused the right eye to be depressed and the left eye to be elevated, the same movement which results from rotating the animal to the left around its longitudinal axis, and this resulted whether the stimulus was applied to the otolith of the right or left ear. The method of stimulation just described very soon injured the delicate otolith and the movements could only be obtained a few times. When, however, I placed a small pellet of wet absorbent cotton on the otolith I could with fine forceps pull the pellet backward or forward or from side to side repeatedly without apparent injury to the otolith. When the cotton was pulled to the right the right eye went down, when pulled to the left the left eye went down, when pulled forward the eyes rolled forward on their axis, when pulled backward both eyes rolled backward.

The above experiment shows that the a priori assignment of different functions to different otoliths with reference to the planes in which they lie and the rotational movements of the body to which they correspond does not accord with the facts. All the compensatory movements and positions arising from vestibular stimulation are obtained from this otolith alone. Parker's and my previous observation that the large otolith of the sacculus is not concerned in equilibrium is confirmed. It is of interest, too, to note that the otolith of each ear gives rise to complementary movements in both directions; elevation of the right and depression of the left eye, or depression of the right eye and elevation of the left eye can be obtained from the otolith of either ear.

\section{THE MECHANISM OF THE PHYSIOLOGICAL}

\section{ACTION OF THE OTOLITH ORGANS}

It has been almost universally believed since the publication of the earlier papers of Mach and Breuer that in the otolith organs the normal stimulus is the pressure due to the weight of the otolith resting on the sensitive macular epithelium; when the position of the head is changed the pressure is shifted to a different part of the macula and a different set of impulses is sent to the muscle groups concerned. This conception has been greatly strengthened by the work of Delage, Kreidl and others on the otocysts of invertebrates. But as $I$ have shown in the preceding section stimulation experiments show with the utmost clearness and regularity results which are exactly the reverse of those which should follow if the pressure theory were true. In describing these experiments $I$ have been repeatedly stopped to answer the question, "Don't you mean 'to the right' when you say "to the left'?" or, "Don't you mean 'backwards' instead of 'forwards'?" When the normal animal is rotated around its longitudinal axis, to say $30^{\circ}$ to the right, the right eye goes up and the left eye goes down. When the body is in this position the weight of the otolith in each ear must be shifted to the right. But when the right side of the otolith is pressed upon or when the cotton is 
pulled to the right exactly the opposite movement of the eyes results. If as commonly believed, the stimulus is the pressure due to the weight of the otolith, and if that pressure, shifted to right by inclining the body to the right acts by stimulating more strongly the epithelium on the right hand side surely the artificial application of pressure should produce the same result but just the reverse actually happens. I believe that the actual process is as follows: When the right side of the otolith is pressed upon it is displaced to the left just as one saucer standing in another is displaced to the left when one pushes straight down on its right hand margin. This, then, is the same displacement as that which occurs when the body is tilted to the left. It is not the pressure but the displacement due to the weight of the otolith which brings about the normal stimulus. It is the direction of the displacement which determines the direction of the resulting compensatory movement. I have ventured to suggest that the displacement gives rise to differences of tension which act on the sensory structures in a manner analogous to the effects of different tensions on the vagus endings in the lungs. It will be seen in the following section that this wholly unexpected result is in accord with the conclusions which I had previously reached in regard to the mode of stimulation of the ampullæ.

\section{THE MECHANISM OF THE PHYSIOLOGICAL STIMULATION OF THE AMPULLE}

An adequate discussion of the enormous literature of this subject would far exceed the limits of this paper. Nearly half a century ago Mach, Breuer and Brown almost simultaneously published papers suggesting that each canal functioned for the recognition of rotational movements in its own plane. Roughly stated the assumption was that rotation of the head in the plane of any canal would tend by the inertia of the fluid within the canal to produce a current in the direction opposite to that of the rotation. In the popular literature and in many of the text-books a favorite statement of the theory is about as follows: Each rotation of the head in the plane of any canal causes through the inertia of the endolymph a current in the canal in a direction counter to the rotation. The hair cells of the ampullæ stick out like paddles and are deflected in the direction of the current. The bending of the hair cells exerts pressure on the nerve endings and produces the stimulus. Mach, however, was too good a physicist to believe that a current could be produced under the conditions existing in the semicircular canals. He found that water placed in a glass model of the dimensions of a human semicircular canal showed no perceptible current when rotating at a reasonable speed. He affirmed on theoretical grounds that rotation could cause a pressure but denied the possibility of an actual current. Breuer (1899) also found on anatomical grounds that the theory in this form is not tenable, for the hair cells do not project into the endolymph, but are embedded in the gelatinous mass of substance forming the cupula. In more recent years Rossi (1914) has constructed a model of the dimensions of a human canal and has been able to demonstrate some movement of the contained liquid when rotated; but the rate of rotation necessary to produce visible movement is far beyond the order of magnitude of the rate giving a distinct physiological reaction. Moreover, according to the very beautiful anatomical work of A. A. Gray (1907-08) the semicircular canals in the squirrel and the rat have each a diameter only $1 / 5$ as great as in man. These animals show no inferiority in labyrinthine reactions. In order to form a satisfactory demonstration it would be necessary to make the external diameter of the tube in the model $0.25 \mathrm{~mm}$. I have found (1912) that in the horned lizard, Phrynosoma, rotation at an angular velocity so slow as a movement through $45^{\circ}$ in 8 seconds caused a distinct labyrinthine reflex. Under these circumstances a current is unthinkable.

Direct experiment on the canals is more to the point than the foregoing theoretical considerations. Loeb (1891) cut through or excised portions of the canals in the dogfish 
and found that no disturbance of righting reactions resulted. Ewald (1892) plugged and cut the canals in the pigeon without throwing them out of function.

I have ligatured, cut and plugged the canals in the dogfish (1910) without in the least disturbing their functions. But I have put the canal current theory to a more decisive test (1919). In the dogfish the compensatory movements to rotation in the horizontal plane are mediated only by the ampullæ of the horizontal canals, and each acts only for rotation toward its own side. If one horizontal ampulla, say the left, is removed, rotation to the right around the dorsoventral axis causes both eyes to deviate to the left, but rotation to the left has no effect. I exposed a right horizontal canal for nearly its whole length, cut it through as near as possible to its posterior connection with the vestibule, then without injuring its connection with its ampulla I raised it up and fixed it in the vertical plane at right angles to the longitudinal body axis. It is evident that with the canal in this new position rotation in a horizontal plane could not cause a current in its endolymph. But rotation to the right around the dorsoventral axis actually caused both eyes to deviate to the left, while rotation to the right (or left) around the longitudinal axis, that is in the plane of the new position of the canal, did not cause such a movement. It is evident that under the conditions of the experiment rotation in a horizontal plane could not possibly produce a current in the canal, and hence the stimulation must have been produced in some other way.

Since no further consideration need be given to the idea that the excitation on rotation is due to currents in the semicircular canals, we may briefly consider other possible causes. These might be effects due to (1) the inertia of the mass of fluid in the vestibule, or (2) due to the inertia of the ampullar contents, or (3) due to the inertia of the sensory cells themselves. The second and third of these possibilities are eliminated by the fact that when the membranous connec- tion of the utriculus has been cut off the compensatory movements to rotation in the horizontal plane are entirely absent although the motions can be as easily elicited as ever by mechanical stimulation.

Since the transection of the utriculus abolishes the reflex it is clear that the utricular (and possibly the saccular) structures are an essential part of the mechanism. It is to be noted that the direction of rotation which acts as a stimulus to any canal is that which carries foremost the side of the ampulla bearing the crista. In looking over the large number of figures given by Retzius and by A. A. Gray I find no exception to this rule. The mouths of the canals at their ampullar ends are so connected with the vestibular parts of the membraneous labyrinth that the inertia effect of the mass of liquid (endolymph and perilymph) in the vestibule must cause an increase of tension on the part of the ampulla bearing the crista when a rotation is made in the direction in which the crista leads. A careful examination of the anatomical relations will show that even if it were possible for the inertia effect of rotation to cause a movement of liquid in the canal and thus exert a pressure on the cupula (the hair cells of course could not be acted upon directly), a much greater effect must be produced on the membranous structures in the vestibule. The relatively large mass of liquid in the vestibule with its proportionally small surface area exposed to the friction of the walls must show more inertia effect during rotation than the small amount of liquid in the canal with its proportionally large area of contact with the canal walls. The membranes which form the sacculus and utriculus are virtually stretched through the mass of liquid in the vestibule and must necessarily be put under tension when any rotational movement is given to the liquid.

If the above conception is the correct one it should be true that change of tension and not change of pressure should act as the stimulus. I had previously shown by experiments on Phrynosoma (1912) that the pressure due to centrifugal force has nothing to 
do with the excitation. When the animal was placed with its head $25 \mathrm{~mm}$. from the center of rotation it required no greater rate of rotation to act as a stimulus than when the head was $300 \mathrm{~mm}$. from the center. The centrifugal force in the latter position is 12 times as great as in the former, but the angular velocity and hence the torsion effect was the same in the two positions.

Convection currents due to a difference in temperature on the two sides of the vestibule could much more conceivably occur in the liquid of the vestibule than in the canals. The nystagmus movements described by Högyes as a result of irrigating the external ear of man and many animals with hot or cold water and the change of character of the nystagmus by change of position of the head can best be accounted for by the changes of density of the liquid in the vestibule. The reliability of Bárány's use of these phenomena for diagnostic purposes is not affected by the acceptance of this view, but only his unscientific explanation must be abandoned.

I wish in closing to draw attention to the fact that a survey of all the experimental work on the labyrinth leads to the conclusion that the stimulation of the vestibular structures and of the sensory endings in the ampullæ depend upon the same principle, namely the effects of changes of relative tensions. How the change of tension excites the nerve endings and what part if any the hair cells play in the process still remains wholly outside the field of experimental investigation.

\section{UNIVERSITT OF CALIFORNIA}

\section{S. S. Maxweli}

Brever, J.

$$
\text { REFERENCES }
$$

1899. Ueber die Bogengansampullen. Zen-

Gray, Albert A. tralblatt für Physiol., 13: 750.

1907-8. The labyrinths of animals. London, J. A. Churchill.

Kubo, Ino.

1906. Ueber die vom N. acusticus ausgelösten. Augenbewegungen. II. Versuche an Fischen. Arch. f. d. ges. Physiol., 115: 457.
Lee, Frederic $\mathbf{S}$.

1893. A study of the sense of equilibrium in fishes. Journal of Physiol., 15: 311.

Loeb, J.

1891. Ueber Geotropismus bei Thieren. Arch. f. d. ges. Physiol., 49: 175.

Maxwell, $\mathbf{s}$. S.

1910. Experiments on the functions of the internal ear. Univ. of Calif. Pub. in Physiol., 4: 1 .

1912. On the exciting cause of compensatory movements. Am. Jour. of Physiol., 29: 367.

1919. Labyrinth and Equilibrium. I. A com. parison of the effect of removal of the otolith organs and of the semicircular canals. Jour. of Gen. Physiol., 2: 123.

1920a. Labyrinth and Equilibrium. II. The mechanism of the dynamic functions of the labyrinth. Jour. of Gen. Physiol., 2: 349 .

1920b. Labyrinth and Equilibrium. III. The mechanism of the static functions of the labyrinth. Jour. of Gen. Physiol., 3: 157.

Parker, G. H.

1909. Influence of the eyes, ears and other allied sense organs on the movements of the dogfish, Mustelus Canis (Mitchill). Bull. Bureau of Fisheries, 29: 43.

Rossi, G.

1914. Di un modello per studiare gli spostamenti della endolinfa nei canali semicircolari. Arch. di Fisiol., 12 : 349.

\section{MEETING OF THE GENETICISTS INTERESTED IN AGRICULTURE}

IN conjunction with the meetings of the American Association for the Advancement of Science and affiliated societies in Chicago an informal gathering of instructors and investigators of genetics related to agriculture was held December 28th at the University of Chicago. Some thirty-five representatives from fifteen Agricultural Colleges and Experiment Stations, the United States Department of Agriculture and other institutions were present. Unfortunately the impossibility of getting the final notices out until very late prevented a number of others from attending. The purpose of the meeting was to discuss such topics of mutual interest at this time as 